\title{
Mardin-Hırbe Helale Alt Paleolitik Dönem Yontmataş Buluntuları
}

\author{
Ergül KODAŞ¹; Bülent GENÇ²; Bahattin İPEK³
}

Atıf/C): Kodaş, Ergül; Genç, Bülent; İpek Bahattin, Mardin-Hırbe Helale Alt Paleolitik Dönem Yontmataş Buluntuları, Artuklu İnsan ve Toplum Bilim Dergisi 2020/5 (1), 53-59.

$\ddot{0} \mathbf{z}$

Hırbe Helale yerleşim yeri, Mardin-Diyarbakır karayolu güzergâhının 6. kilometresinin batısında yer alan Mardin ili Artuklu ilçesi sınırlarında Mardin Artuklu Üniversitesi yerleşkesi içerisinde yer almaktadır. Mardin Artuklu Üniversitesi Kampüs alanı içerisinde bulunan arkeolojik alanda yapılan araştırmalar söz konusu alanın Paleolitik Çağ, Geç Roma Dönemi, Bizans Dönemi ve Artuklu Dönemi gibi birbirinden farklı dönemlerde yerleşim görmüş olduğunu göstermektedir. Yerleşim yerinde ele geçen Alt Paleolitik Dönem buluntular dönemin yontma taş tekno-tipolojisi ve bölgenin kronolojik ve kültürel yapılanması hakkında önemli bilgiler vermektedir. Özellikle Alt Paleolitik Dönem'e tarihlenen yontmataş aletler bölgenin kronolojik yapısının incelenmesi için önem arzetmektedir. Hırbe Helale'de ele geçmiş olan çakıl taşı aletler, el baltaları, nacaklar, yonga üzeri aletler ve yonga çekirdekleri yerleşim yerinin Alt Paleolitik Dönem aşölyen kültürü ve öncesine tarihlendiğini düşündürmektedir. Hırbe Helale yerleşim yeri aynı zamanda, jeolojik olarak, Asya ve Afrika Bloku'nun birleştiği bir konumda yer alan Tur Abdin ile Suriye Stepleri arasında doğal geçiş üzerinde bulunmaktadır. Bu bağlamda insanoğlunun Afrika'da çıkış teorileri üzerine de önemli bilgiler verecek bir potansiyele sahiptir.

Anahtar Kelimeler: Hırbe Helale, Alt Paleolitik, Aşölyen, Yongalama.

\section{Chipped Stone Remains the Lower Paleolithic Period at Mardin-Hırbe Helale}

Citation/C): Kodaş, Ergül; Genç, Bülent; İpek Bahattin, Chipped Stone Remains the Lower Paleolithic Period at Mardin-Hırbe Helale, Artuklu Human and Social Science Journal 2020/5 (1), 53-59.

\section{Abstract}

Hurbe Helale is located in the Mardin Artuklu University campus on the borders of the Artuklu district of Mardin, which is located west of the 6 kilometers of the Mardin-Diyarbakir highway route. The archaeological researches in the campus area of Mardin Artuklu University show that the area in question was settled at different periods such as Paleolithic Age, Late Roman Period, Byzantine Period and Artuklu Period. The finds from the Lower Paleolithic Period in the settlement provide important information on the chipped stone technology of the period and on the chronological and cultural structure of the region. The chipped stone tools, especially dating to the Lower Paleolithic Period, are important for the study of the chronological structure of the region. Pebble tools, hand axes, nachos, chipped tools and cores finds in Hirba Helale suggest that the settlement was dated both to the Lower Paleolithic period Acheulean culture and before. In addition, Hirbe Helale is located on the natural transition way between Tur Abdin and the Syrian Steppes,

\footnotetext{
${ }^{1}$ Dr. Öğr. Üyesi, Mardin Artuklu Üniversitesi, Edebiyat Fakültesi, Arkeoloji Bölümü, Sorumlu Yazar (Corresponding Author): ergulkodas@gmail.com, ORCID: Orcid.org/0000-0001-8340-5828.

2 Dr. Öğr. Üyesi, Mardin Artuklu Üniversitesi, Edebiyat Fakültesi, Arkeoloji Bölümü, bulendgenc@hotmail.com, ORCID: Orcid.org/0000-0002-1529-6831.

3 Arş. Gör., Mardin Artuklu Üniversitesi, Edebiyat Fakültesi, Arkeoloji Bölümü, bahattinipek47@gmail.com, ORCID: Orcid.org/0000-0003-4380-9283.

Geliş/Received: 21.02 .2020 , Kabul/Accepted: 07.06 .2020
} 
which is located geographically in a location where the Asian and African Blocks meet. In this context, it has the potential to give important information on the cultural diffusion of human beings from Africa.

Keywords: Hirbe Helale, Lower Paleolithic, Acheulean, Chipping.

\section{GİRiş}

Hırbe Helale yerleşim yeri Mardin-Diyarbakır karayolu güzergâhının 6. kilometresinin batısında yer alan ve Mardin/Artuklu ilçesine bağlı olan Akbaş Köyü sınırları içerisinde bulunmaktadır. Yerleşim yeri 2009 yılında tespit edilmiş ve tescile alınmıştır. Bu bağlamda 2010, 2011 ve 2018 yıllarında Mardin Müze'si tarafından Artuklu Üniversitesi Kampüs alanında birtakım kurtarma kazıları ve sondaj çalışmaları yapılmıştır. Bilhassa 2018 yılında yapılan arkeolojik çalışmalar sırasında alanda Paleolitik Dönem'e tarihlenen çok sayıda yontmataş alet yerinde fotoğraflanmış veya toplanmıştır. Bu çalışma 2018 yılında Güzel Sanatlar Fakültesi otoparkı önünde yapılan sondaj kazıları sırasında, kontekstleri bozulmuş olan, toplanan ve yine aynı yıl kampüs ve çevresinde bulunan alanlarda toplama yapmadan arazide fotoğraflanan Alt Paleolitik Dönem yontmataş aletleri üzerine yapılan incelemelerin genel tanıtımıdır. Hırbe Helale ismiyle bilinen yerleşim yeri bugün Artuklu Üniversitesi Kampüs Yerleşkesi ile anılmakla birlikte aslında çok daha geniş bir alanı kapsamaktadır. Yaklaşık olarak $80000 \mathrm{~m}^{2}{ }^{\prime}$ lik bir alanı kaplayan söz konusu açık hava yerleşim yeri özellikle Mardin-Artuklu Üniversitesi Kampüs Yerleşkesi içerisinde bulunan alanda daha çok Paleolitik Çağ ile MS 4-5. yüzyıl ve MS. 12-14. Yüzyıla tarihlenen buluntular yoğun olmakla birlikte Artuklu Üniversitesi Kampüs Yerleşkesi'nin doğusunda kalan alan daha çok Paleolitik Çăg'a ait yontmataş kalıntıları ile temsil edilmektedir.

$\mathrm{Bu}$ bağlamda üniversite yerleşkesinin dışında kalan, kuzey, güney ve batı yönlerindeki alanlarda da yine Paleolitik Çağ'a tarihlenen çok sayıda yontmataş alet tespit edilmiştir. Yerleşim yerinin bulunduğu alanın coğrafik konumuna bakıldığında ise Şekil 1'de de görülebildiği gibi Hırbe Helale açık hava yerleşim yerinin Kızıltepe Ovası'nın kuzeyinde bulunan Diyarbakır istikametine doğru açılan vadilerden, Qurs Vadisi ile birleşen bir vadi üzerinde bulunduğu görülmektedir. Bu bağlamda Hırbe Helale yerleşim yeri güneyde jeolojik olarak Afrika blokunun parçası olan ve deniz seviyesinden yaklaşık 500 metre yükseklikte bulunan Kızıltepe Ovası, kuzeyde ise deniz seviyesinden yaklaşık 1000-1200 metre yükseklikte olan dağlarla sınırlanmaktadır. Bunun yanı sıra Şekil 1 'de de görüldüğü gibi Cizre Ovası'ndan Şanlıurfa'ya doğru doğu-batı yönünde uzanan söz konusu ovadan kuzey yöndeki dağlık bölgeye geçiş sağlayan-çok sayıda derin vadi ve küçük $1 \mathrm{rmak}$ (Beyazsu, Karasu, Zergan, Çırçıp, vb.) bulunmaktadır ${ }^{4}$ ve Hırbe Helale yerleşim yeri de söz konusu geçişlerden birisi olan Qurs Vadisi’nin kuzeyinde bulunmaktadır.

\footnotetext{
${ }^{4}$ Özellikle Kızlttepe-Derik arasında yaklaşık 500-550 metre yükseklikte olan ovadan deniz seviyesinden 1000 metre ve üzerine çıkan kuzeydoğu ve kuzeydeki dağlık bölgeye, özellikle Diyarbakır’a doğru, geçiş sağlayan çok sayıda küçük vadi bulunmaktadır.
} 
Şekil 1: Hırbe Helale yerleşim yerinin lokalizasyonu ve bölgede bulunan doğal geçiş yolları

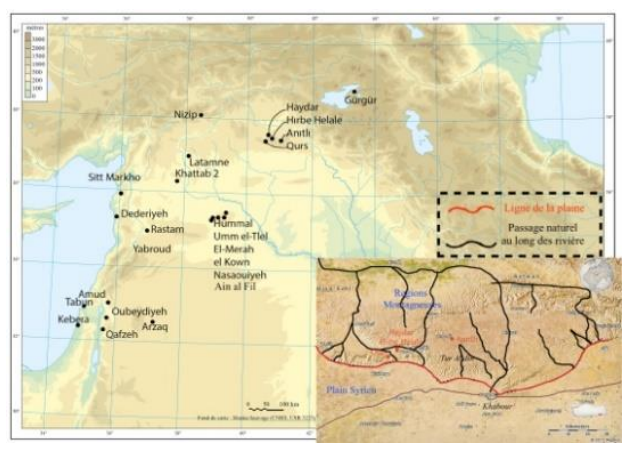

\section{Alt Paleolitik Dönem Yontmataş Buluntular}

Hırbe Helale Paleolitik Çă̆ yerleşim yerinde alanın genelini belgelemek için yapılan araştırmalar sırasında, özellikle bu süreçte çekilen fotoğraflara bakıldığında, yerleşimin önemli bir bölümünde, özellikle vadinin merkezine doğru kalan çoğu alanda metrekare başına yer yer 300-400 adet yontmataş kalıntısının (alet veya atık) olduğu görülmektedir. Bu noktada yine inşaat ve yol çalışmaları sonrası ortaya çıkan profiller üzerinde yine $20-30 \mathrm{~cm}$ derinliğinde olan arkeolojik tabakalar hala görülebilmektedir. Bir açık alan yerleşim yeri olan Hırbe Helale'nin çakmaktaş1 yataklarının üzerinde olduğu ve bir yontmataş alet üretim alanı olarak kullanılmış olabileceği de düşünüldüğünde bu durum şaşırtıcı değildir ${ }^{5}$. Yerleşim yerinin kronolojik gelişimine baktığımızda ise yerinde fotoğraflanan veya alanda toplanan yontmataş buluntular yerleşim yerinin bilhassa Alt Paleolitik Dönem (yaklaşık MÖ 1,7 milyon- MÖ 350 bin) veya Orta Paleolitik Dönem'e (yaklaşık MÖ 350-45 bin arası) tarihlendiğini göstermektedir. Hırbe Helale yerleşim yerinde aynı zamanda Üst Paleolitik Dönem'e tarihlenen az sayıda yontmataş alet kalıntısı ve bilhassa Geç Kalkolitik Dönem'de baskı yöntemi ile dilgi üretimine işaret eden çakmaktaşı dilgi ve bu dilgilerin üretildiği çok sayıda dilgi çekirdeği tespit edilmiştir.

Bu çalışma kapsamında incelenen Alt Paleolitik Dönem yontmataş buluntuları arasında ise iki yüzeyli aletler yoğun olmakla birlikte dönemin erken evrelerine tarihlenen yontuk çakıltaşı aletler (Chopper ve Chopping) ve bu döneme ait yongalı kültürlere ait çok sayıda yontmataş alet ve üretim atı̆̆ı (iki yüzeylilerle temsil edilen Acheuléen kültüre nazaran az sayıda olmakla birlikte) tespit edilmiştir. Tipolojik ve teknolojik bağlamda bakıldığında Alt Paleolitik Dönem'i üç ayrı yontmataş alet kültürü üzerinden incelemek yanlış olmayacaktır: Pebble-Core, Chopper ve Chopping ve Biface. Ayrıca yerleşim yerinde Levallois yonga üretimine ait çok sayıda buluntu tespit edilmiş olmakla birlikte söz konusu buluntuların tarihlendirilebilmesi için bazı kronolojik sorunlar mevcut olduğundan (Orta Paleolitik'te de bu üretim yönteminin devam etmesi ve elimizde tarihlendirmelerin olmamasından dolayı) söz konusu buluntular bu çalı̧̧a içerisinde incelenmemiştir.

\section{Çaytaşı yonga çekirdekleri, satır ve kıyıcılar (Pebble-Core ve Chopper/Chopping)}

Yerleşim yerinde tespit edilen yontuk çaytaşı aletler arasında, Şekil 2'de de görüldüğü gibi, iki yüzeyleri biçimlendirilmiş olan (façonnage) ve literatürde chopping tools olarak isimlendirilen aletler (satırlar) daha yoğundur. Fakat alanda tek yüzeyi biçimlendirilmiş olan çok sayıda chopper (kıyıcı) da tespit edilmiştir. Alanda yine yontuk çakıltaşı aletlerin üretimi sırasında ortaya çıkan

\footnotetext{
${ }^{5}$ Yerleşim tercihinde hiç kuşkusuz rol oynayan diğer bir durum ise yerleşim yerinin sadece açık hava yerleşimi değil aynı zamanda bir çakmaktaşı yatağı olmasıdır. Alanda bulunan kalker katmanlar içerisinde genellikle devetüyü renginde olan doğal çakmaktaşı yumruları bulunmaktadır. Aynı zamanda yer yer pembemsi ve açık kahverengimsi bloklara da rastlanmaktadır. Bu bağlamda söz konusu alan hem açık hava yerleşim yeri hem de yontmataş alet üretim atölyesi gibi düşünülebilir.
} 
birçok yonga da tespit edilmiştir. Söz konusu aletler Alt Paleolitik Dönem'in erken evrelerinde yoğun olmakla birlikte bu dönemin ilerleyen evrelerinde ve hatta yer yer Orta Paleolitik Dönem'de de kullanılmaya devam etmektedir. Bu nedenle söz konusu aletleri tarihlendirmek ayrı bir sorun oluşturmaktadır.

Şekil 2: Tek veya iki yüzeyi şekillendirilmiş yontuk çakıltaşı aletler (Hırbe Helale Kazı Arşivi)
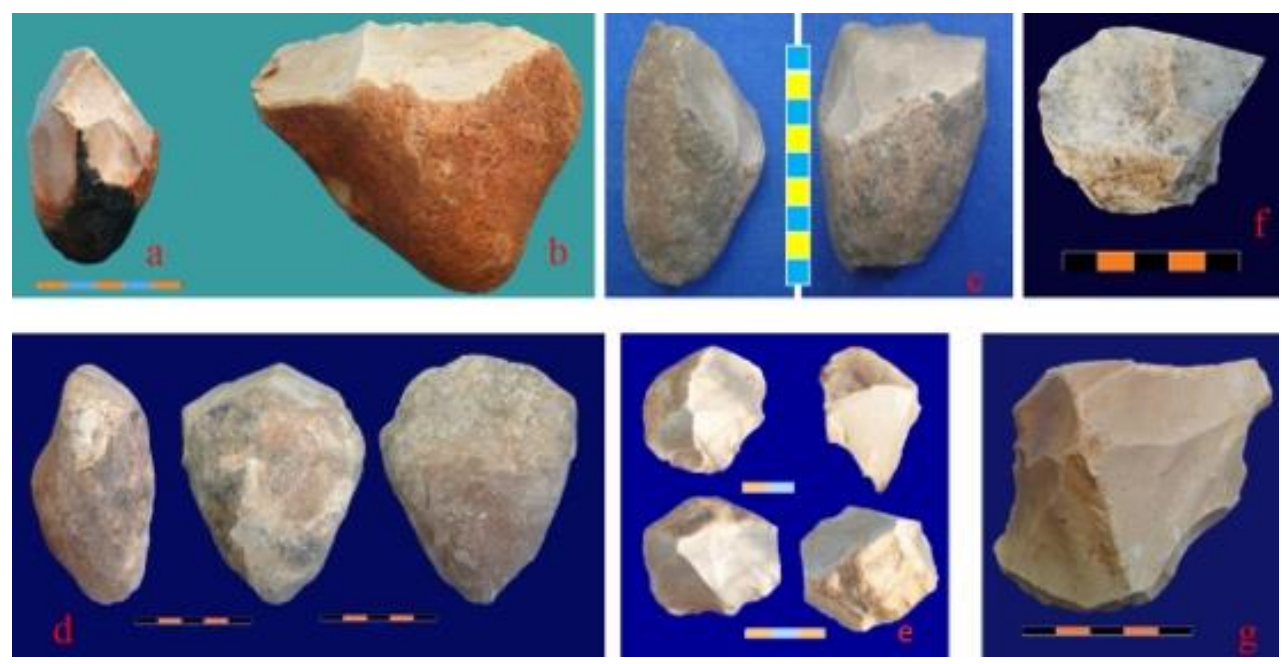

Bu nedenle Alt Paleolitik Dönem'e tarihlendiği düşünülen söz konusu aletlerin bu dönemin hangi evresine ait olduklarını bildirmek şu an için sorunlu olmakla birlikte Şekil 2'te görüldügü gibi yerleşim yerinde ele geçen ve Alt Paleolitik Dönem'in erken evrelerine tarihlenen çok sayıdaki yongalama çekirdeği (discoid, polyhedron, vb.) bu bağlamda hem yerleşim yerinin ilk iskan tarihini hem de yontuk çakıltaşı aletlerin tarihlendirilebilmesi için daha detaylı bilgiler vermektedir. Özellikle Şekil 3'te de görüldüğü üzere tayacien kültürüne ait olan kaba kortikal yongalar, tayac uçları, tayac tipi düzeltili küçük yongalar ve değişik formlardaki pebble-core'lar alanın Alt Paleolitik Dönem erken evrelerinden beri (Paléolithique inferieur, ante-acheuléen) ziyaret edildiğini düşündürmektedir. Fakat tayaciyen tipi yongalar yoğun olmakla birlikte yerleşim yerinde henüz clactonien tipi yonga üretimine dair herhangi bir yontmataş alet bulunamamıştır. Kronolojik ve bölgesel bağlamda bakıldığında ise Hırbe Helale yerleşim yerinde ele geçen yonga üretimine ait öz konusu buluntular özellikle Suriye'de El-Kowm bölgesinde bulunan Hummal yerleşiminin Acheuléen öncesi tabakalarından ele geçen (Ante-Acheuléen), fakat henüz tam olarak tarihlendirilememiş olan, yontmataş buluntularla yoğun bir benzerlik göstermektedir (Le Tensorer ve dĭg., 2005; Shea, 2016; Muhesen, 2012; Boeda, 2019). Bu bağlamda Hirbe Helale yerleşim yerinden ele geçen yontmataş buluntular (pebble-core, chopper-chopping) için kesin bir dönem bildirmek şu an için zor görünmekle birlikte, Suriye'de ele geçen bu dönem buluntular ile bir arada düşünüldüğünde, Hırbe Helale yerleşim yerinin de Acheuléen Kültür öncesine tarihlenebileceği anlaşılmaktadır. 
Şekil 3: Tayac kültürü yontmataş kalıntıları (Hırbe Helale Kazı Arşivi)

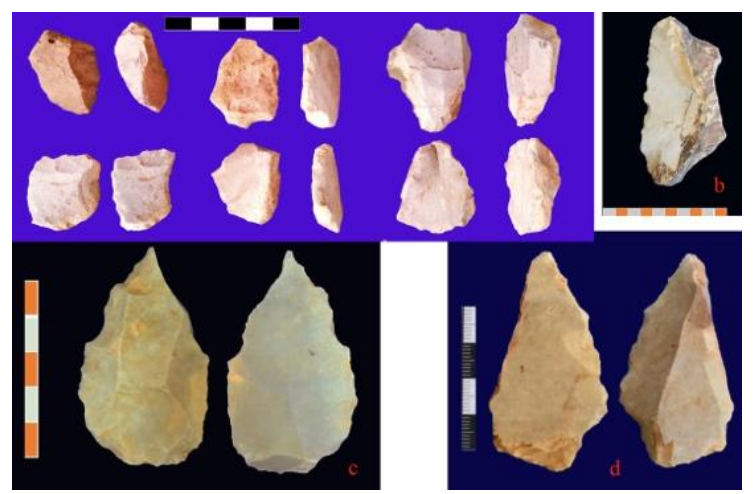

\section{Bifaslar ve Acheuléen Kültürü}

Alt Paleolitik Dönem'e tarihlenen iki yüzeyli alet (Biface kültürlerine ait yontmataş aletlere bakıldığında ise yerleşim yerinde ele geçen buluntular arasında hem tipolojik hem de kronolojik bağlamda önemli bir çeşitliliğin olduğu gözlemlenmektedir. Şekil 4'te de görüldüğü gibi, özellikle tipolojik bağlamda bakıldığında, Hırbe Helale'de tespit edilen iki yüzeyliler arasında simetrik olan üçgenimsi, kalp biçimli (klasik, uzun ve yarıkalp biçimli), badem biçimli, oval, naviform, laganiform ve abbevilien tipi bifaslar daha yoğundur (Bordes, 1968; Otte ve di ̌̆., 1998).

Şekil 4: Hırbe Helale'den ele geçen iki yüzeyliler (Bifaslar, Hırbe Helale Kazı Arşivi)
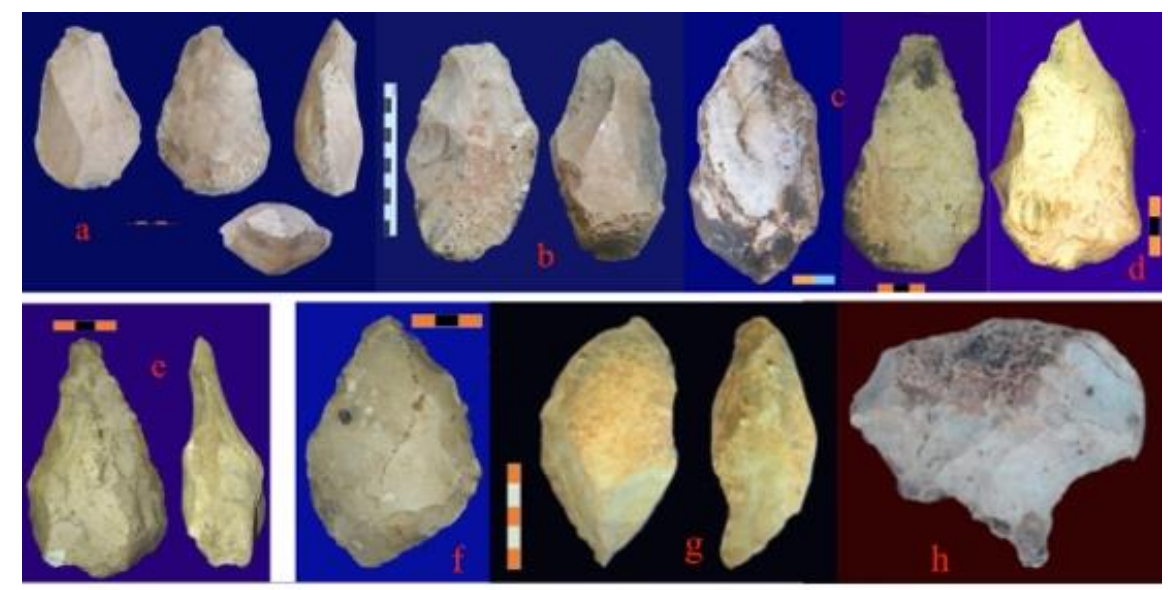

Yerleşim yerinin tarihlendirilmesi için öne çıkan diğer bir yontmataş alet topluluğu ise Şekil 5'te görüldüğü gibi Erken ve Orta Acheuléen Dönem'e tarihlenen çok sayıda nacağın varlığıdır (Hachereau). Bunlardan bazıları yonga üzerine yapılmış olmakla birlikte bazıları direkt olarak çakmaktaşı yumrular üzerine yapılmıştır. Yumru üzerine yapılan bu tip nacaklar daha çok Erken Acheuléen Dönem'e tarihlendirilmektedir (Bordes 1968, Otte ve Nioret 2010). 
Şekil 5: Hırbe Helale'den ele geçen nacaklar Hırbe Helale Kazı Arşivi)
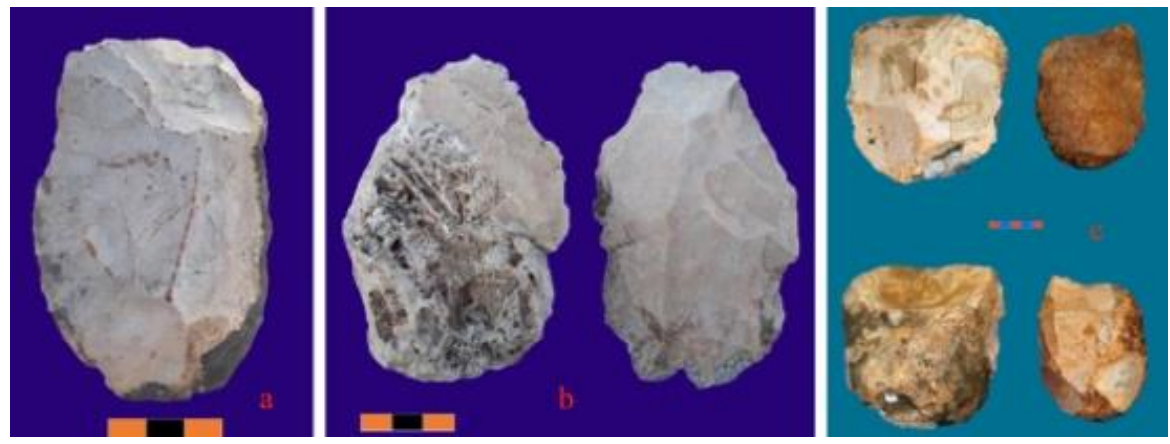

Bu bağlamda Şekil 6'da görüldüğü gibi proto-bifas olarak da isimlendirilen abbeviliyen tipi iki yüzeylilerin varlığı yine Alt Paleolitik Dönem Erken Acheuléen Kültür'ün varlığına işaret etmektedir (Bar-Yosef ve Belfer-Cohen, 2001; Muhesen, 2012; Shea, 2016). Orta Acheuléen Kültüre ait daha simetrik olan badem biçimli ve oval formda olan iki yüzeyliler, kazmalar (pique) ve az sayıda üç yüzeyli (triedre) alet bulunmaktadır (Bordes, 1968; Shea 2016; Otte ve Nioret, 2010). Geç Acheuléen Kültüre gelindiğinde ise Şekil 4'te de görüldüğü gibi ince işçilik kalitesine sahip olan çok sayıda iki yüzeyli alet tespit edilmiştir.

Şekil 6: Hırbe Helale'den ele geçen proto-bifaslar (Hırbe Helale Kazı Arşivi)
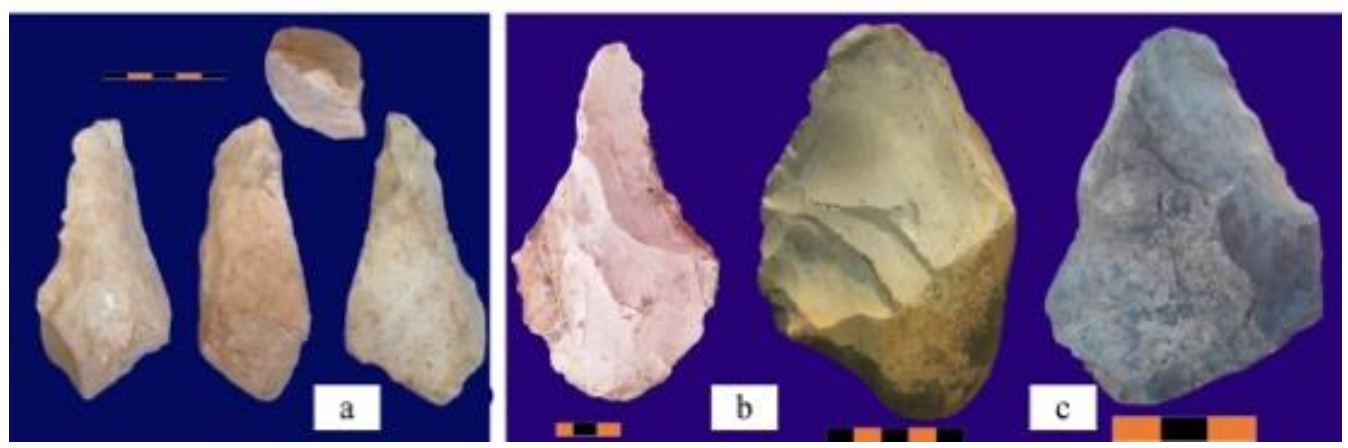

\section{SONUÇ}

Yerleşim yerinde toplanan veya yerinde fotoğraflanarak incelenen elde edilen mevcut veriler, Hırbe Helale yerleşim yerinin Alt ve Orta Paleolitik Dönem'de yoğun olarak ziyaret edildiğine işaret etmektedir. Hırbe Helale yerleşiminde tespit edilen (yerinde fotoğraflanan veya toplanan) Paleolitik Çağ yontmataş aletler ve atıkları Güneydoğu Anadolu'da yüzey araştırmalarıyla sınırlı kalan (Taşkıran, 2008; Dinçer, 2016) Alt Paleolitik Dönem kültürlerinin Suriye üzerinden Anadolu'ya, Kafkasya'ya ve Asya'ya yayılımı hakkında referans oluşturacak niteliktedir. Bilhassa yerleşim yerinde yoğun olarak ele geçen değişik form ve boyutlardaki iki yüzeyli aletler, yontuk çakıltaş1 aletler, nacaklar, levallois yongalama çekirdekleri ve yongaları, Yabrud Kültürü yonga çekirdekleri ve Hummaliyan Kültürü yontmataş buluntular yerleşimin kronolojik gelişiminin incelenmesi için önemli bilgiler vermektedir.

Jeocoğrafik olarak bakıldığında Afrika Bloku ile Asya Bloku arasında bulunan ve çakmaktaş1 kaynakları açısından zengin bir yapı sergileyen Hırbe Helale yerleşim yerinin Güneydoğu 


$$
\text { E. } K O D A S ̧-B . G E N C ̧-B . \dot{I P E K}
$$

Anadolu'da az bilinen Paleolitik Çağ kültürlerinin incelenmesi içim hem kronolojik hem de kültürel bağlamda zengin bir yapı sergilediği görülmektedir. Özellikle Alt Paleolitik Dönem'de Afrika'dan çıkan insanoğlunun Avrasya’ya yayılım yolu üzerinde bulunan (Bar-Yosef ve Belfer- Cohen, 2001) Mardin Bölgesi bu dönem kültürlerinin incelenmesi için önemli bir potansiyele sahiptir. Bu bağlamda Hırbe Helale Paleolitik Çağ yerleşim yeri Anadolu ile Suriye arasında bulunan ve Afrika'dan Avrasya'ya doğru, Levant Bölgesi üzerinden, yayılım gösteren Alt Paleolitik Dönem kültürlerinin incelenmesi için ayrı bir önem teşkil etmektedir.

\section{KAYNAKÇA}

Bar-Yosef, O. - Belfer-Cohen A. (2001). From Africa to Eurasia: early dispersals. Quaternary International, C. 75, s. 19-28.

Boeda, E. (2019). Integrer le temps long pour mieux apprehender le changement technique en prehistoire. Antropologie des techniaues. Chaier, C. 1, s. 63-76.

Bordes, F. (1968). La Paléolithique dans le monde. Paris: Univers des connaissances.

Dinçer, B. (2016). The Lower Paleolithic in Turkey: Anatolia and Hominin Dispersals Out of Africa. Paleoanthropology of the Balkans and Anatolia. Human Evolution and its Context. (Ed. K. Harvati - M. Roksandic). Dordrecht: Springer. s. 213-228.

Le Tensorer, J. - Hauck, M. - Wojtczak, D. B. (2005). Le Paléolithique ancien et moyen d'Hummal (El Kowm, Syrie centrale). Swiattowit, C. 5, s. 179-194.

Muhesen, S. (2012). Aperçu sur le Paléolithique de Syrie. Syria, C. 89, s. 7-29.

Otte, M. - Noiret, P. (2010). Les gestes techniques de la préhistoire. Bruxelles: De Boeck.

Otte, M. - Yalçınkaya, I. - Kozlowski, J. - Bar-Yosef, O. - Bayón, L. L. - Taşkıran, H. (1998).

Long-term technical evolution and human remains in the Anatolian Palaeolithic. Journal of Human Evolution, C. 34, s. 413-431.

Shea, J. J. (2016). Stone Tools in Human Evolution: Behavioral Differences among Technological Primates Paperback. Cambridge: Cambridge University Press.

Taşkıran, H. (2008). Réflexions sur l'Acheuléen d'Anatolie. L'Anthropologie, C. 112, s.140-158. 